\title{
Paediatric crossword puzzle 32
}

Manouri P Senanayake ${ }^{1}$, Arjuna Atapattu ${ }^{2}$

Sri Lanka Journal of Child Health, 2016; 45(3): 233

DOI: http://dx.doi.org/10.4038/sljch.v45i3.8152

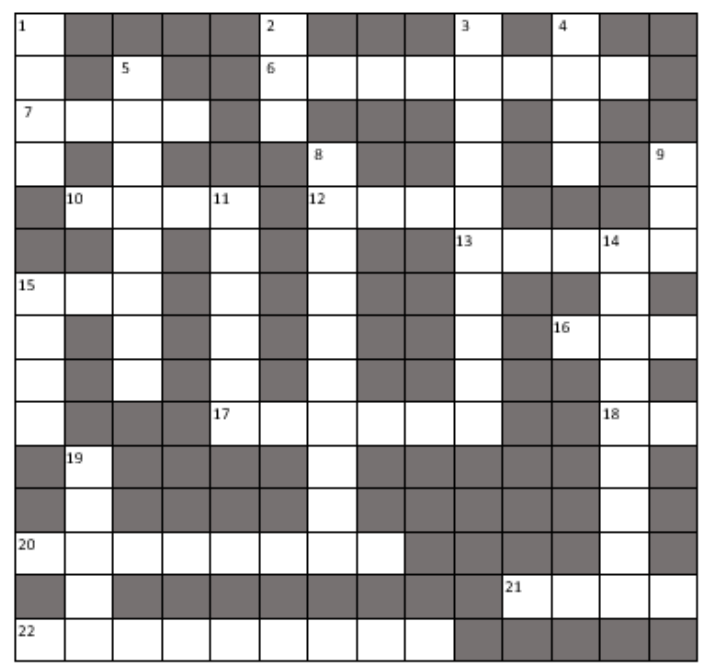

ACROSS

6. Investigation after three months of iron therapy

7. Zinc protoporphyrin increases in red cells in poisoning

10. Condition overlapping with cognitive difficulty and autism

12. Hospital acquired infection is ..........comial

13. Mosquito that transmits Zika virus

15. Measure of body fat taking height, age and sex into account

16. Syndrome of thrombocytopaenia and absent radius

17. Every months has days in the

Bayley Scales

18. Screening needed in children with historical refugee camp stay

20. Raised ZPP levels occur in haemolytic anaemia with red cell ....

21. Important organ for surveillance in Neurofibromatosis 1

22. Anticonvulsant that should be used with caution in infants and with metabolic disorders

\section{DOWN}

1. Statistical hypothesis proposing no difference 2. AST, ALT are included in biochemical investigation (abbrv)

3. Genetic test that should require consent from parents

4. In iron deficiency, a ....... ion is incorporated into haem

5. Gait due to severe bowing of legs

8. Possible reason for acute wheezing to not settle by salbutamol nebulization

9. Neurological disease implicated as associated with Zika viral infection (abbrv)

11. Previously normal infant with a genetic epilepsy syndrome commonly originating following immunization

14. Stool test indicative of pancreatic deficiency 15. Insects producing source of botulinum poison

19. Public health risk of microcephaly is caused by

${ }^{1}$ Department of Paediatrics, Faculty of Medicine, Colombo

${ }^{2}$ University Paediatric Unit, Lady Ridgeway Hospital for Children, Colombo 